\title{
DO NACIONALISMO ROMÂNTICO À LITERATURA REGIONAL: A REGIÃO COMO PÁTRIA
}

\section{FROM THE NACIONALISTIC ROMANTICISM TO THE REGIONALISTIC LITERATURE: THE REGION AS HOMELAND}

\section{João Claudio Arendt}

RESUMO: Neste artigo, discutem-se aspectos relacionados ao caráter nacionalista da Literatura Brasileira durante o Romantismo e os seus desdobramentos em forma de manifestações literárias regionais. Com base em depoimentos de escritores como Gonçalves de Magalhães, Gonçalves Dias, José de Alencar, Bernardo Taveira Júnior, Guimarães Rosa e Simões Lopes Neto, procura-se mapear algumas causas para a regionalização da literatura e a transformação da região em uma espécie de pátria dentro da nação. $\mathrm{O}$ aporte teórico oriundo da Geografia Cultural contribui para fundamentar a discussão.

PALAVRAS-CHAVE: Literatura brasileira; Romantismo; Região; Nação; Pátria

ABSTRACT: This article discusses aspects related to the nationalist nature of Brazilian Literature during Romanticism and its development into regional literary expression. Based on statements by writers such as Gonçalves de Magalhães, Gonçalves Dias, José de Alencar, Bernardo Taveira Júnior, Guimarães Rosa and Simões Lopes Neto, it intends to map some causes for the regionalization of literature and the transformation of the region into a kind of homeland inside the nation. The theoretical approach from Cultural Geography contributes to support the discussion.

KEYWORDS: Brazilian literatur; Romanticism; Nation; Region; Homeland

\footnotetext{
* Doutor em Letras pela PUCRS. Professor no Programa de Mestrado em Letras, Cultura e Regionalidade da Universidade de Caxias do Sul PPGLET/UCS. Diretor da revista eletrônica Antares (Letras e Humanidades).jcarendt@ucs.br
} 


\section{I.}

Se a Carta de Pero Vaz de Caminha é escrita e endereçada ao rei de Portugal, Dom Manuel, em 1500, e O uraguai, de Basílio da Gama, dedicado em 1769 ao Conde de Oeiras (o diplomata e primeiro-ministro de Portugal, Sebastião José de Carvalho e Melo), o livro que oficialmente inaugura o Romantismo brasileiro, Suspiros poéticos e saudades (1836), de Gonçalves de Magalhães, vai como tributo "à Pátria, enquanto lhe não oferecemos cousa de melhor valia". "Vai - diz o poeta - nós te enviamos, cheio de amor pela pátria" (1974, p.29). O mesmo se verifica com Os timbiras, de 1857, que Gonçalves Dias oferece "à majestade do muito alto e muito poderoso príncipe, o senhor D. Pedro II, imperador constitucional e defensor perpétuo do Brasil".

Trata-se, nos dois primeiros exemplos, de construir e manter uma relação de pertencimento e de filiação política e literária da colônia brasileira à metrópole portuguesa, ao longo de um processo que duraria um pouco mais de três séculos. Nos outros dois casos, vislumbra-se, por sua vez, a estruturação de um sentimento de pertença à recém independente nação brasileira, em contraposição aos antigos laços com Portugal. Ou, como afirma Candido, trata-se de "um sentimento de libertação relativamente à mãe-pátria (...) tarefa patriótica na construção nacional (...) que se aponta ao escritor como estímulo e dever" (2000, p.12). Após a independência, as representações do campo literário modificam significativamente o seu foco, direcionando-se agora à pátria brasileira, no sentido de erigir e solidificar símbolos capazes de, ao mesmo tempo, amplificá-la e sintetizá-la. 


\section{II.}

No Rio Grande do Sul, desenvolve-se, logo após a publicação de $O$ gaúcho, de Alencar, um movimento de forte regionalização da literatura, seguido de uma particularização dos temas, visível também nas autoridades e no público a que as obras se destinam. Assim é que, em 1873, Bernardo Taveira Júnior entrega As provincianas "ao povo rio-grandense (...) São elas as pobres lucubrações de um rude engenho, que tem a mania de fazer da poesia uma das suas maiores delícias na terra. Salve província do Rio Grande do Sul!" (1986, p.23). De modo semelhante, o poeta Lobo da Costa, em 1874, é animado por dois grandes sentimentos ao publicar suas Lucubrações: "o de enviar à minha cara província alguns rastos de meu peregrinar e deixar nesta terra heróica e hospitaleira, um mimo de respeito e saudade" (1991, p.32).

Enquanto Bernardo Taveira Júnior responde diretamente à representação do gaúcho elaborada por José de Alencar, Lobo da Costa, ao que parece, sente-se mobilizado pela orientação do amigo Carlos Ferreira que, residindo em São Paulo, aconselha o poeta a mandar o livro "à nossa bela província do Rio Grande do Sul onde há, como aqui, uma mocidade entusiasta e altiva que estuda e produz, ainda que completamente desconhecida dos corifeus da literatura brasileira na capital do Império" (1974, p.32).

É muito provável que a "terrível centralização política e administrativa", no dizer de Carlos Ferreira, que se estende até os domínios da literatura, seja igualmente responsável pelo redimensionamento do foco literário para a Província de São Pedro do Rio Grande. Para o missivista, "raro livro de escritor de província consegue captar a atenção dos atarefados escritores da corte", além de que "todo e qualquer cometimento intelectual que for produzido fora do grande centro, não entra lá, não vale a pena ser assinalado, não recebe, portanto, a consagração de uma simples notícia de jornal ao menos" (1991, p.32).

Assim, se o sentimento nacionalista alimentado e propagado pelos românticos do centro se espraia como norma geral até as várias províncias brasileiras, a inserção dos autores provincianos na corte parece não se efetivar, contribuindo, dessa maneira, para o processo de regionalização da literatura. Trata-se, em última instância, de um movimento que deriva e, ao mesmo tempo, se opõe ao centro, num escopo muito próximo daquele que moveu os primeiros românticos nacionalistas em relação a Portugal. A mesma falta de atenção imputada aos portugueses é sentida agora pelas províncias em relação ao centro do país. 
III.

De um modo geral, o Brasil, nos primórdios do Romantismo, assume a feição de uma ampla região americana em grande parte ainda desconhecida pela pena dos seus poetas e prosadores, os quais, segundo Gonçalves de Magalhães, dilatavam "seu vôo até as margens do Tejo" e emparelhavam “com as Tágides no canto" (1974, p.22). É a região do Tejo, em Portugal, que durante muito tempo se conecta por meio de um cordão sentimental aos escritores brasileiros, os quais "se metamorfoseiam em pastores da Arcádia, e vão apascentar seus rebanhos imaginários nas margens do Tejo, e cantar à sombra das faias" (1974, p.20). Todavia, em razão da independência e da idéia de pátria, que "domina tudo, e tudo se faz por ela, ou em seu nome" (1974, p.22), as "encanecidas montanhas da Europa" agora humilham-se "diante das sempre verdes e alterosas montanhas do Novo Mundo" (1974, p.21). A poesia brasileira anterior ao Romantismo não passava de "uma grega vestida à francesa e à portuguesa, e climatizada no Brasil" (1974, p.19); ou de uma virgem de Hélicon que, peregrinando pelo mundo, sentou-se "à sombra das palmeiras da América" e, embevecida com a reminiscências da pátria, "toma[va] por um rouxinol o sabiá que gorjeia[eava] entre os galhos de uma laranjeira" (1974, p.20).

O caso Alencar, nessa perspectiva, é bastante significativo deste movimento dialético de contemplação da pátria e de regionalização literária. Depois de escrever sobre o Rio de Janeiro e ficcionalizar aspectos da história do Brasil, José de Alencar debruça-se intencionalmente sobre os espaços periféricos do país para, encetando um projeto nacionalista, uni-los ao "centro" e, dessa forma, fortificá-lo. A justificativa para este projeto parece ser explicitada no prefácio a Sonhos d’ouro, de 1872, quando, avaliando a produção literária brasileira e montando o painel da sua própria produção ficcional, declara: "Paleta, onde o pintor deita laivos de cores diferentes, que juntas e mescladas entre si, dão uma nova tinta de tons mais delicados, tal é a nossa sociedade atualmente" (1974, p.121). E acrescenta: "Notamse aí, através do gênio brasileiro, umas vezes embebendo-se dele, outras invadindo-o, traços de várias nacionalidades adventícias", que, em última análise, formam "a nova e grande nacionalidade brasileira" (1974, p.121).

É assim que os seus dois primeiros romances - Cinco minutos, 1856, e A viuvinha, 1857 - têm ambientação carioca, e o romance histórico O guarani, também de 1857, situa geograficamente seu enredo às margens do rio Paquequer, principal afluente do Paraíba do Sul, no município fluminense de Sumidouro. Lucíola (1862), Diva (1864) e A pata da Gazela (do início 
da década de 1870) têm igualmente a "fisionomia da sociedade fluminense, que aí está a faceirar-se pelas salas e ruas com atavios parisienses, falando a algemia universal, que é a língua do progresso, jargão erriçado de termos franceses, ingleses, italianos e agora também alemães" (1974, p.121).

$\mathrm{Na}$ década de 1870, considerando aqueles lugares do país "onde não se propaga com rapidez a luz da civilização" (1974, p.120), Alencar publica os seguintes romances de temática rural: O tronco do ipê (1871), Til (1872), O gaúcho (1870) e O sertanejo (1875). Todavia, o próprio romancista admite que $O$ tronco do ipê, "devido à proximidade da corte e à data mais recente", traz as marcas e "a influência da nova cidade, que de dia em dia se modifica e se repassa do espírito forasteiro" (1974, p.121). Deduz-se, a partir daí, que a contrapartida da faceirice urbana, dos atavios parisienses, da algemia universal e do progresso localiza-se espacialmente no meio rural do Sudeste (com o caipira), do Sul (com o gaúcho) e do Nordeste (com o sertanejo) - onde, repita-se, "não se propaga com rapidez a luz da civilização" e se encontra "ainda em pureza original, sem mescla, esse viver de nossos pais, tradições, costumes, e linguagem, com um sainete todo brasileiro" (1974, p.120).

Embora Alencar esteja munido de boas intenções "brasilistas"1 (e não necessariamente patrióticas, já que critica aqueles "que tomam a sério estas futilidades de patriotismo, e professam a nacionalidade como uma religião" [1974, p.120]), no sentido de se opor à recolonização do Brasil "pela alma e pelo coração, já que não o podem pelo braço" (1974, p.120), ele se encontra no "centro" do país e seu ponto de vista discursivo deixa entrever o lugar de sua enunciação. $\mathrm{O}$ resultado da construção desse painel nacional foi, definitivamente, a fratura da nação em regiões, especialmente no que tange à Província do Rio Grande do Sul, onde os intelectuais, insatisfeitos com os caracteres (a suposta artificialidade) que lhes são atribuídos, encetam um movimento de repúdio às representações oriundas do "centro" do país. A literatura regional nasce, portanto, do mesmo embrião da literatura nacional, mas no sentido de uma contra-corrente.

\footnotetext{
${ }^{1}$ Esta denominação corre, aqui, por conta de Afrânio Coutinho, que afirma: "Alencar é o modelo da corrente que se pode chamar 'brasilista' em oposição aos 'ocidentalistas'. Estes últimos insistem nas raízes ocidentais, brancas da nossa civilização e cultura; enquanto os primeiros acentuam o lado nativista, brasileiro, construído pelos brasileiros, numa situação geográfica, racial, histórica e social diferente, um novo complexo cultural". (1974, p.68)
} 
Quem se confronta, por exemplo, com a nota "Convém ler", redigida por Bernardo Taveira Júnior, em 05 de janeiro de 1873, ao seu livro de poemas As provincianas, pode ter uma noção mais exata deste aspecto. Afirma o poeta que uma coisa apenas dirá a favor de si: "é que poetizei sobre cousas que me passaram pelos olhos, e das quais tenho pleno conhecimento". (...) Ninguém escreva sobre o que não conhece ou viu, ou ainda confiado em informações destituídas de toda a verossimilhança" (1986, p.21). O que Taveira Júnior parece ressaltar nesse depoimento é a relação de proximidade entre o criador e o universo a ser representado, ou seja, a familiaridade, na sua opinião, indispensável à própria verossimilhança da obra. Por isso, afirma o poeta, quem "lê O gaúcho de Sênio [Alencar], ri-se e chacoteia da impropriedade e ridículo com que é apresentado em cena" (1986, p.21).

Para o autor de As provincianas, não há problema algum na fantasia, desde que o escritor tenha por tema a verdade. Desse modo, por desconhecer as particularidades da cultura sulina e sua paisagem, Alencar teria naufragado em sua fantasia e criado "um pseudogaúcho". O romancista incorreu, portanto, no erro de não "visitar a nossa terra, de estudá-la e conhecê-la" a fundo. Assim, autointitulando-se porta-voz da verdadeira cultura gaúcha, Bernardo Taveira Júnior compõe em sua obra um painel do universo campeiro, exaltando-o com o mesmo tom romântico-alencariano. Sobressaem aí o Rio Grande do sul e os seus campos; o canto do gaúcho; o vaqueano, o tropeiro, o laçador, o boleador, o camponês e o domador; o rancho, as carreiras e a marcação.

O sentimento que envolve o poeta "provinciano" em nada difere daquele que impulsionou os escritores do "centro" a exaltarem a paisagem, a linguagem e os tipos humanos brasileiros. Se o projeto romântico, no seu estágio embrionário, encetou a tarefa de exaltar a paisagem brasileira, idealizando a sua juventude e vigor em contraposição às ruínas do Velho Mundo, a percepção "da impropriedade e do ridículo", bem como da falta de "verossimilhança" resultante da ampla diversidade territorial, contribuiu para uma fragmentação do país em surtos literários regionais. A regionalização dessa literatura passa, inicialmente, por um sentimento de integração à nação, tal como ainda se vê em José de Alencar, mas aos poucos as diferentes regiões tomam ares de uma autonomia que conduz à emancipação das representações de paisagem. A literatura regional nasce, portanto, também da impossibilidade de os escritores amalgamarem a diversidade paisagística do Brasil. 
Um exemplo significativo de exaltação da paisagem brasileira pode ser encontrado no "Discurso sobre a história literária do Brasil" (1836), de Gonçalves de Magalhães:

Este imenso país da América, debaixo do mais belo céu, cortado de tão pujantes rios, que sobre leitos de ouro e pedras preciosas rolam suas águas caudalosas; este vasto terreno revestido de eternas matas, onde o ar está sempre embalsamado com o perfume de tão peregrinas flores, que em chuveiros se despencam dos verdes docéis pelo entrelaçamento formado dos ramos de mil espécies, estes desertos, remansos, onde se anuncia vida por esta voz solitária da cascata que se despenha; por esse doce murmúrio das auras, que se embalançam nas folhas das palmeiras, por essa harmonia grave e melancólica das aves, e dos quadrúpedes; este vasto Éden separado por enormíssimas montanhas sempre esmaltadas de verdura, em cujo tope, colocado se crê o homem no espaço, mais chegado ao céu, que à terra, e debaixo de seus pés vendo desnovelar-se as nuvens, roncar as tormentas, e disparar o raio; com tão felizes disposições da Natureza o Brasil necessariamente inspirar devera seu primeiros habitadores; os Brasileiros músicos, e poetas nascer deviam. Quem o duvida? Eles o foram, eles ainda o são. (1974, p.24)

O tom de exaltação que emana das palavras de Gonçalves de Magalhães associa-se ao coro dos políticos e intelectuais que, naquele contexto de recente independência, procura minar os atributos do continente a que Portugal se conecta do ponto vista geográfico. De modo indireto, o autor de Suspiros poéticos e saudades desprestigia a natureza européia, interpondo à percepção dos brasileiros um país novo, de abundantes e inesgotáveis recursos naturais, com uma incomparável beleza paisagística a inspirar eternas lucubrações poéticas e musicais, inclusive as dos seus habitantes nativos, especialmente dos "Tamoios, que no Rio de Janeiro habitavam" e "eram os mais talentosos" (1974, p.24).

Na mesma perspectiva posteriormente adotada por Alencar, Gonçalves de Magalhães assume um discurso centralizado e por demais homogeneizador, por isso incapaz de dar conta da diversidade territorial brasileira. E a referência à paisagem nacional, uma espécie de corografia poéticogeográfica, não traduz nenhuma particularidade territorial: vagas referências ao céu, aos rios, às matas, ao ar, às flores, às aves, aos animais quadrúpedes. Uma descrição mistificada, semelhante a um "vasto Éden" bíblico, imprecisamente localizado numa América mítica e habitado por "Brasileiros músicos". Como propõe Zilberman (1994, p.29), o líder do 
grupo da Revista Niterói "repete noções próprias ao mito paradisíaco, ao louvar o verdor das matas e a perfeição dos ares, designar a região de 'vasto Éden' e alardear a pujança do solo e a riqueza mineral".

Não há aqui, portanto, referências concretas e precisas à diversidade territorial brasileira: tudo ainda se mescla num único amálgama improvisado que objetiva formatar uma unidade nacional não necessariamente geográfica, mas especialmente sentimental. A única menção de Gonçalves de Magalhães à palavra "região" ocorre no momento em que censura o caráter passadista da poesia brasileira, que se deixa subjugar por "leis arbitrárias", que "imita alheios pensamentos". Na sua opinião, é "como se a natureza se ostentasse a mesma em todas as 'regiões', e diversos sendo os costumes, as religiões e as crenças, só a poesia não pudesse participar dessa variedade, nem devesse exprimi-la" (1974, p.25-26).

A idéia de região que aí se formula vai ao encontro, sem dúvida, da noção de diversidade das paisagens humanas que marcará a geografia cultural européia surgida no final do século XIX. Todavia, Gonçalves de Magalhães ainda não está propondo uma divisão do Brasil em regiões, mas apenas comparando dois espaços geográficos muito amplos, que ele evasivamente intitula como regiões: a América e a Europa. E essa leitura se confirma com o fato de que a primeira divisão geográfica do país aconteceria somente em 1913, pela mão de Delgado de Carvalho, com base em elementos físicos e posições geográficas.

\section{IV.}

As regiões brasileiras não surgiram por acaso, nem a literatura regionalizou-se da noite para o dia seguinte. Quando na década de 1840 Gonçalves Dias defende, com paixão, também a criação de uma língua brasileira, o país já está sob o impulso do Romantismo e da fermentação de idéias independentistas que se desdobram em diferentes direções. $\mathrm{O}$ autor de I-Juca Pirama perfila-se favoravelmente à nacionalização da língua, sob o argumento de que "a nossa Flora, a nossa Zoologia, a nossa Topografia" (1974, p.65) poderiam protestar, caso se desprezasse "a língua tupi", que "lançou profundíssimas raízes no português que falamos" (1974, p.65). E aqui estaria em jogo não apenas a expressão literária, mas também a comunicação cotidiana dos brasileiros: "Se querem dizer coisas que não há em Portugal, que se não lêem nos dicionários, como diabo se há de exprimir?" (1974, p.65). Trata-se de uma significativa quantidade de termos indígenas e africanos, relacionados à comida, à pesca e à lavoura, quase que unicamente empregados na conversação cotidiana. 
Ao mesmo tempo, Gonçalves Dias admite a existência, no país, de variedades lingüísticas capazes de particularizar a comunicação e a expressão poética: "Acontece também que em distâncias tão consideráveis como são as do Brasil, o teor de vida muda; e os homens que adotam esta ou aquela maneira de viver formaram uma linguagem própria sua, mas expressiva e variada" (1974, p.65). Disso se pode depreender, portanto, que, sob o argumento da extensão territorial do país, emergem idiossincrasias lingüísticas (e culturais) impossíveis de serem abrigadas por um único léxico, urbano e centralizado na corte, e muito menos pela língua portuguesa ultramarina. Entre os exemplos, o poeta cita os vaqueiros, os mineiros, os pescadores e os "homens da navegação fluvial".

Gonçalves Dias sugere, ainda, a pertinência tanto da representação literária dessas particularidades culturais quanto da utilização, na ficção, das linguagens com que cotidianamente os diferentes grupos se expressam: "Pois o romance brasileiro não há-de poder desenhar nenhum destes tipos, porque lhe faltam os termos próprios no português clássico?” (1974, p.65). Não há referências no seu discurso de à palavra "região", mas se notam os particularismos brasileiros que serviriam de gérmen para o posterior florescimento das literaturas regionais. A língua, conforme o próprio entendimento dos escritores daquela época, constitui, ao mesmo tempo, a ferramenta de pesquisa e o instrumento de expressão por excelência de um escritor. Logo, infere-se que conhecer a língua nacional e suas manifestações mais localizadas é mister para o desenvolvimento de uma literatura brasileira capaz de expressar seu variado conjunto humano e cultural.

Chama a atenção, mais uma vez na literatura produzida no Rio Grande do Sul, o fato de, em 1847, Caldre e Fião sub-intitular - "intencionalmente", na opinião de Chaves (1992, p.9) - a sua obra $A$ divina pastora como "novella rio-grandense", atribuindo-lhe uma informação geográfica e delimitando-lhe um espaço particularizado de ambientação. Nessa época, ainda estava em vigor a divisão política do país com base nas províncias e não se fazia uso do termo "região" para nominar os diferentes espaços geográficos brasileiros. Embora não faça, como sugere Chaves, nenhuma menção ao termo gaúcho, "o autor mantinha acesa a chama do seu amor pelo Rio Grande do Sul" (1992, p.9), ao mesmo tempo em que se associava à busca de uma identidade própria para o Brasil e assinalava "o ingresso do gaúcho no território da ficção brasileira, precisamente em 1847” (1992, p.15; grifo original).

Aproximando melhor o depoimento de Chaves do ângulo de análise deste trabalho, é possível afirmar que A divina pastora constitui uma das 
primeiras manifestações regionalizadas da prosa romântica brasileira, atestando assim a descentralização da criação literária e o desmembramento do discurso patriótico na direção das províncias. Sub-intitular um romance como "novella rio-grandense" significa demarcar uma posição política num momento histórico de grande animosidade, como o que foi provocado pela Revolução Farroupilha (1835-45). A nação vai, aos poucos einevitavelmente, se regionalizando na e através da literatura.

Outro caso exemplar da literatura do Rio Grande do Sul é o da poeta Delfina Benigna da Cunha, com suas Poesias oferecidas às senhoras riograndenses, publicadas em 1843, na mesma época em que Gonçalves de Magalhães trazia a lume os seus Suspiros poéticos e saudades. Trata-se da primeira obra editada em prelos gaúchos, a Tipografia Fonseca, de Porto Alegre. Entretanto, instaura-se, nesta obra, uma espécie de paradoxo na relação entre a "província" e "centro": ao mesmo tempo em que muitos poemas são dedicados à figura do Imperador e à família real, o volume é explicitamente direcionado, em seu título, a um grupo específico de leitores: as senhoras rio-grandenses. Em contrapartida, e aí o paradoxo se avoluma, algumas composições criticam severamente Bento Gonçalves da Silva, líder da Revolução Farroupilha.

É possível que a vinculação dos poemas à corte se deva ao fato de a poeta, órfã e cega desde criança, ter recebido ajuda financeira do imperador para sua manutenção. Entretanto, à parte os aspectos biográficos, a obra nitidamente configura um público particularizado na então Província de São Pedro do Rio Grande. Isso significa, mais uma vez, que existia uma tendência à literatura brasileira se regionalizar, mesmo que, no caso de Delfina, não se efetive um discurso laudatório da Província, mas sim da corte situada no Rio de Janeiro. E a dedicatória ao público feminino riograndense, repita-se, é prova concreta disso.

\section{V.}

No prólogo de Iracema, em 1865, José de Alencar, faz considerações acerca da elaboração e da possível recepção do romance ao seu amigo, Dr. Jaguaribe, que se encontra no Ceará. Um dos aspectos aí posto em relevo diz respeito à relação do romancista com sua terra natal: "Os meninos brincam na sombra do outão com pequenos ossos de reses, que figuram a boiada. Era assim que eu brincava, há quatro anos, em outro sítio, não muito distante do seu" (1974, p.102). É o "amor do ninho" que vincula Alencar ao espaço rural do Ceará, uma espécie de laço sentimental que nem o tempo e a distância 
conseguem romper - cuja razão talvez se encontre no fato de as relações dos homens com o espaço terem uma dimensão psicológica e sociopsicológica: "Nascem das sensações que as pessoas experimentam e das percepções a elas ligadas" (CLAVAL, 2001, p.39). Isso porque, de um modo geral, "a experiência do espaço é feita por meio dos sentidos humanos" (CLAVAL, 2001,p.61). São as chamadas geografias vividas, ou experimentadas através da visão, do olfato, do tato, da audição e da gustação.

Daí que, ao mesmo tempo em que dele emana a inspiração da pátria, "o livro é cearense", porque "foi imaginado aí, na limpidez desse céu de cristalino azul, e depois vazado no coração cheio de recordações vivazes de uma inspiração virgem" (1974, p.102). A declaração de Alencar deixa entrever o alto teor de subjetividade que pode existir na relação entre autor, obra e espaço - este último, uma espécie de berço para o escritor, sobre o qual o "semblante materno" eternamente lhe sorri. Mas, ao mesmo tempo, o romancista receia que, "assim mandado por um filho ausente, para muitos estranho, esquecido talvez dos poucos amigos e só lembrado pela incessante desafeição, qual sorte será a do livro?” (1974, p.102). Enviá-lo ao seu patrício constitui, portanto, uma espécie de retorno simbólico do autor ao torrão natal, reavivando recordações que o inspiram e a ele se conectam umbilicalmente.

Surgida de uma visita de Alencar à terra natal em 1848, a obra materializaria suas "idéias a respeito da literatura nacional", porque nela se encontraria uma "poesia inteiramente brasileira, haurida na língua dos selvagens" (1974, p.106). E aqui é interessante chamar a atenção sobre a relação que Alencar estabelece entre a pátria e a Província do Ceará: parece, por um lado, que ambas se fundem homogeneamente, podendo-se, sem prejuízo algum, tomar uma pela outra; por outro lado, é possível dizer, também, que esta última, por seus atributos humanos e naturais, constitui, num processo metonímico, uma parte que se conecta ao todo e contribui valorosamente para a grandeza da pátria.

Ao mesmo tempo, Alencar encontra-se fisicamente estabelecido na cidade do Rio de Janeiro, então centro político e administrativo do império. Forma-se, a partir daí, um triângulo sentimental muito interessante, exatamente nesta ordem: a Pátria, o Rio de Janeiro e Ceará. A primeira, em vias de construção coletiva e motivo de grande parte dos seus esforços intelectuais, tanto na criação quanto na crítica literária, é antes uma idéia vaga e abstrata, ainda por se delinear com maior precisão; a segunda toma ares um pouco mais reais e conecta-se à vivência cotidiana do escritor, às 
experiências mais próximas. O Rio de Janeiro é, simultaneamente, a sua trincheira e a sua tribuna - e mirante de onde contempla cheio de ufanismos a pátria e lança o olhar saudoso em direção à terra natal. Ceará, por sua vez, constitui aquele espaço umbilical e simbólico ao qual Alencar se conecta sentimentalmente em razão do nascimento e das experiências de infância, e que na idade adulta transforma-se numa espécie de idade de ouro para sempre perdida. "Estou certo que o filho de minha alma [o romance] achará na terra de seu pai a intimidade e conchego da família" - afirma o escritor na anteriormente referida "Carta sobre Iracema", endereçada ao amigo cearense, Dr. Jaguaribe.

VI.

Quando, em 1912, Simões Lopes Neto torna público o volume de Contos gauchescos, ele revela, na "Apresentação", motivos referentes à escolha do tema e do espaço para a ambientação das suas narrativas. Uma "digressão longa e demorada, feita em etapas de datas diferentes", uma espécie de cruzada "em caprichosos ziguezagues" pelo território do Rio Grande do Sul, permitiu que conhecesse o litoral, as ilhas da Lagoa Mirim, a coxilha de Santana, o soberbo Rio Uruguai, as penedias do Caverá, as planícies do Saicã, as águas grandes do Ibicuí, a fortaleza de Santa Tecla, as paragens magníficas de Tupanciretã, a graciosa Santa Maria, os extremos de Passo Fundo, os cumes da Lagoa Vermelha, a merencória Soledade e a zona colonial.

Do ponto de vista da paisagem humana, o autor afirma ter visto, com seus "pobres olhos condenados à morte, ao desaparecimento", o curral, o pomar, o rebanho, a seara, as manufaturas, as cidades, os rostos, as crianças e os sulcos do arado. E tudo isso, em forma de uma "visão sublimada e consoladora", que os mesmos olhos "guardarão na retina até o último milésimo de luz". Trata-se, na perspectiva do autor, de uma "impressão vivaz e maravilhosa da grandeza, da uberdade, da hospitalidade" encontradas em solo gaúcho e que remetem, de modo especial, aos lugares e homens dos tempos heróicos.

Tem-se aí, no depoimento do escritor, uma amostra da relação de familiaridade que se estabelece entre o autor e o mundo que ele propõe representar. Dela emerge, por sua vez, a afetividade que o conduz a conclamar "a raça que se está formando" a amar e glorificar o passado histórico gaúcho. Não restam dúvidas, também no caso de Simões Lopes, acerca do seu envolvimento emocional com o mundo narrado, de maneira que a escolha deste 
último tem como baliza ingredientes de tal modo subjetivos e pessoais, que o levam a idealizá-lo com requintes muito próximos aos dos românticos do século XIX.

Entretanto, apesar do sentimento de totalidade propalado na "Apresentação", no sentido de procurar abranger a diversidade natural e cultural do Rio Grande do Sul, Simões Lopes restringe seus contos unicamente ao mundo da Campanha, como se o passado e o presente gaúchos fossem formados apenas pelo universo simbólico daquela região. Os eventos narrados, protagonizados ou testemunhados por Blau Nunes desenrolamse na área geográfica dos campos sulinos, onde se desenvolveu a atividade pecuária. A zona colonial, formada pelas imigrações em massa, no século XIX, de alemães e italianos, é completamente ignorada pelas narrativas, como se na história do Rio Grande do Sul elas nunca tivessem existido. Tal postura remete ao requerimento de uma identidade exclusiva e hegemônica - a campeira - para todos os habitantes gaúchos, numa mostra clara de que todos devem se conectar umbilicalmente àquela região do estado que, por seu passado supostamente heróico, reivindica para si o direito de síntese da gauchidade.

\section{VII.}

Na carta ao amigo João Condé, Guimarães Rosa revela alguns segredos sobre a composição de Sagarana, especialmente no que tange à escolha do espaço para a ambientação das novelas que compõem o volume. O primeiro aspecto que chama a atenção refere-se ao fato de o autor ter passado "horas de dias, fechado no quarto, cantando cantigas sertanejas, dialogando com vaqueiros de velha lembrança, 'revendo' paisagens da minha terra, e aboiando para um gado imenso" (1984, p.9), antes de se dedicar à escrita. É como se houvesse a necessidade de travestir-se em vaqueiro, de mergulhar a fundo no seu universo de valores, de aproximar-se ao máximo da matéria a ser narrada, para poder exprimi-la com propriedade. Ademais, porque aquele mundo não lhe é estranho em razão das experiências da infância, trata-se antes de reatar-se pela memória às paisagens da sua terra. E o que segue a etapa de reconexão do cordão umbilical ao interior de Minas Gerais são "sete meses de exaltação, de deslumbramento".

O segundo aspecto que salta aos olhos na carta a João Condé relacionase à escolha do espaço narrativo:

Àquela altura, porém, eu tinha de escolher o terreno onde localizar as minhas 
histórias. Podia ser Barbacena, Belo Horizonte, o Rio, a China, o arquipélago de Neo-Baratária, o espaço astral, ou, mesmo, o pedaço de Minas Gerais que era mais meu. E foi o que preferi. Porque tinha muitas saudades de lá. Porque conhecia um pouco melhor a terra, a gente, bichos, árvores. (...)

Bem, resumindo: ficou resolvido que o livro se passaria no interior de Minas Gerais. (1984, p.8-9)

O "terreno" onde localizar as histórias de Sagarana assenta-se, como se vê, em critérios de natureza tanto subjetiva e sentimental, quanto social. No primeiro caso, entre Barbacena e o espaço astral, o escritor preferiu o pedaço de Minas que era mais seu, por uma razão bastante pessoal: "Porque tinha muitas saudades de lá” (1984, p.8). Assim como Alencar, muitas décadas antes, Guimarães encontra-se afastado da terra natal, fato que possibilita "rever" sua paisagem humana e natural por meio da reminiscência e da saudade. Além disso, a afirmação de que "conhecia um pouco melhor a terra, a gente, bichos, árvores" (1984, p.8) do interior de Minas permite que se mova com maior segurança pela matéria narrada. A saudade e as vivências pessoais tomam, em suma, a forma de um cordão umbilical que reconecta o escritor ao espaço narrativo da sua obra.

O segundo critério mencionado, o de natureza social, engloba o universo humano do interior de Minas Gerais. Sua escolha para a composição das novelas de Sagarana deve-se ao fato de que "o povo do interior - sem convenções, 'poses' - dá melhores personagens de parábolas: lá se vêem bem as reações humanas e a ação do destino" (1984, p.8). Parece, aqui, que a visão do autor acerca do mundo rural mineiro se estabelece na relação com o universo urbano, cujos valores se diferenciam radicalmente daqueles. Ao mesmo tempo, a noção de parábola associa o homem do campo à época dos Evangelhos, como se os seus valores culturais estivessem estagnados no tempo, sem convenções, sem poses, em suma, com relativa complexidade.

O terceiro e último critério diz respeito à paisagem do pedaço de Minas que julga mais seu: "lá se vê bem um rio cair na cachoeira ou contornar a montanha, e as grandes árvores estalarem sob o raio, e cada talo de capim humano rebrotar com a chuva ou se estorricar com a seca" (1984, p.8). A impressão que se tem, com base nesse depoimento, é de que o meio natural revela com mais nitidez e intensidade os ciclos da vida, se comparado com a artificialidade do meio urbano. $\mathrm{O}$ capim assume características humanas quando exposto à chuva ou à seca, e uma árvore estalando sob o impacto de um raio ganha a dimensão de um acontecimento singular. O mundo rural, em razão disso, transforma-se no terreno por excelência da representação literária rosiana. 


\section{VIII.}

A explanação que se fez até aqui teve como propósito trazer à luz aspectos exemplares das relações que os escritores estabelecem com o espaço escolhido para ambientar suas criações literárias e, ao mesmo tempo, as possíveis motivações para essa escolha. Embora se trate de uma questão nem sempre mensurável e por demais especulativa, julgou-se importante ventilá-la um pouco, em vista da sua ancoragem na discussão sobre o espaço regional e seu respectivo valor simbólico.

Em primeiro lugar, observa-se, no rápido percurso diacrônico desde Pero Vaz de Caminha até Guimarães Rosa, que a literatura estabelece vínculos espaciais e territoriais diretos e indiretos. Indiretamente, quando os textos são dedicados, por exemplo, ao Rei Dom Manuel, ao Conde de Oeiras e ao Imperador D. Pedro II, numa alusão aos seus domínios enquanto figuras públicas detentoras de poder político e administrativo sobre o território brasileiro, em momentos diferentes da história. Nesse caso, entre os séculos XV e XVIII, o território era uma propriedade do monarca, cuja "garantia da apropriação advinha da natureza inquestionável dos direitos reais" (ESCOLAR, 1996, p.142). Os vínculos diretos, por sua vez, são perceptíveis na vinculação das obras a um espaço estrito e privilegiado de representação literária, como se demonstrou no caso de Alencar (Ceará), Bernardo Taveira Júnior e Simões Lopes Neto (Rio Grande do Sul), e Guimarães Rosa (Minas Gerais). Não se trata, nesses casos, de enfatizar o reconhecimento do "território nacional", mas de dar visibilidade a espaços em escala cada vez menor: as províncias e/ou os estados e algumas de suas respectivas regiões.

Ao mesmo tempo, no que tange às representações ficcionais do século XIX em diante, é notável o modo como os espaços nacional e regional se territorializam, adquirindo, aos poucos, um status de autonomia: o primeiro, em relação a Portugal; o segundo, em relação à própria nação brasileira. O movimento de apropriação dos espaços e sua transformação em territórios (nacional e regional) possibilita inferir que as representações estão carregadas de apelos simbólicos reveladores das estratégias de poder utilizadas pelos seus atores. Isso porque, segundo Raffestin, "toda construção da realidade é um instrumento de poder" (1993, p.145), em que atores constroem tessituras, nodosidades e redes responsáveis pelas "vizinhanças, acessos, convergências, mas também disjunções, rupturas e distanciamentos que os indivíduos e grupos devem assumir" (1993, p.161). Assim, o território, como propõe Souza, "é fundamentalmente um espaço definido e delimitado por e a partir de relações de poder" (2001, p.78). 
Essas relações de poder tornam-se visíveis ora no discurso de integração das províncias, estados e regiões ao território nacional, ora na marcação das respectivas diferenças. Se, no primeiro caso, os escritores e críticos literários esforçaram-se em prol da autonomia e da legitimação do território nacional - para dar "sentido à identidade nacional do território" (ESCOLAR, 1996, p.146) -, no segundo caso, houve um nítido processo de afirmação das províncias e estados na perspectiva de marcar as suas particularidades geográficas, históricas e culturais. Trata-se daquilo que Escolar chama de construção de "múltiplas e sucessivas escalas de pertencimento geográfico" (1996, p.146).

Tais escalas de pertencimento aos territórios são construídas sob diferentes níveis de envolvimento emocional dos "atores sintagmáticos" (RAFFESTIN, 1993, p.153) - ou de um "autor", que ao dizer as coisas com autoridade "subtrai-as ao arbitrário, sanciona-as, santifica-as, consagraas, fazendo-as existir como dignas de existir" (BOURDIEU, 1998, p.114). Nos exemplos anteriormente explicitados, os territórios produzidos pelos "autores-atores" envolvem escalas de pertencimento nacional, provincial e/ ou estadual e regional, cada um deles com seus recortes elimites estratégicos, exprimindo as relações mantidas com a porção correspondente ao espaço representado. Se, inicialmente, o território nacional é tomado como ícone maior da pátria, demandando exaltadas declarações de amor, abnegação e sacrifícios de toda ordem, num segundo momento, é a província e/ou o estado, recorte territorial em escala um pouco menor, que se transforma em objeto de adoração dos "a(u)tores"; e, finalmente, dentro da lógica até aqui proposta, o território regional assume a forma e a função da pátria.

Trata-se, neste último caso, de um movimento de regionalização que transforma a região em pátria ou, como propõe Joachimsthaler, "a região vivida como a 'pátria"' $(2009$, p.36). Tal como na óptica do nacionalismo, essa significação do espaço regional pressupõe "um sujeito semantizador, que atribui à região uma particularidade como seu sentido. Este sentido constrói identidade, lealdade, proteção e pertencimento, garante e une, prende e protege" (2009, p.31). Ao mesmo tempo esse "sentido" consolida mitos regionais, estereótipos, ritos, hábitos, particularidades lingüísticas e modos de comportamento. "Pátria' significa para o 'homem inevitavelmente territorial' o prender-se nesta particularidade inerente a ele juntamente com o seu próximo. Ele participa, antes de mais nada, desta particularidade pelo fato de que também ele a representa na sua vida" (2009, p.31-32) e a ela igualmente pertence. 
Essa mesma particularidade, que na perspectiva de Lencioni (1999, p.198) dá sentido à idéia de região, contribui para estabelecer a mediação entre o universal e o singular, e entre o global e o local, a partir da produção de significações para o espaço circundante. Desse modo, participar de uma particularidade significativa, a região nesse caso, implica "um sentido afetivo vinculado ao sentimento das pessoas de pertencerem a um determinado lugar" (LENCIONI, 1999, p.198), fato que surge daquilo que Souza chama de "ligações afetivas e de identidade entre um grupo social e seu espaço" (2001, p.78).

Não há como negar, portanto, que a região se inscreve nas disputas coletivas pela primazia espacial (ou nas lutas pela "definição legítima das divisões do mundo social", que "realizam o sentido e o consenso sobre o sentido" [BOURDIEU, 1998, p.113]), vinculadas à construção e apropriação simbólica do território, resultando numa espécie de "pátria ideal". E aqui é possível afirmar que a "regionalidade", definida por Escolar como "a expressão subjetiva das objetivações geográficas e sociais concretas" (1996, p.136), às vezes, assume o sentido da própria "nacionalidade", acabando por obliterar o sentido etimológico desta última. Ao mesmo tempo, a região se articula a aspectos mais subjetivos e individuais, constituindo uma espécie de território ao qual as pessoas se conectam umbilicalmente em razão do nascimento, de experiências, de posições políticas e sociais etc.

Daí emerge, para concluir, o fato de os escritores anteriormente referidos enfatizarem em suas obras diferentes âmbitos escalares de pertencimento simbólico, desde o território nacional até "aquele pedaço de Minas que era mais meu", no dizer de Guimarães Rosa. A nação e a região não deixam de ser constructos humanos resultantes também das relações de afeto (laços umbilicais) que os indivíduos estabelecem com o bairro, a cidade, a paisagem, os itinerários, os mapas, as imagens. "Minha região também é o mundo, para certas atividades, dimensões de deslocamento e afinidades que adquiri em uma época determinada de minha vida" (ESCOLAR, 1996, p.136) - o que, no caso dos escritores, pode ser transposto para a ficção e delinear espaços idealizados, "pátrias" em última análise.

\section{REFERÊNCIAS BIBLIOGRÁFICAS}

ALENCAR, José de. Prólogo de Iracema [1865], in: COUTINHO, Afrânio (Org.). Caminhos do pensamento crítico. Vol.1, Rio de Janeiro: Ed. Americana/Prolivro, 1974. 
. Carta sobre Iracema - ao Dr. Jaguaribe [1865], in: COUTINHO, Afrânio (Org.). Caminhos do pensamento crítico. Vol.1, Rio de Janeiro: Ed. Americana/Prolivro, 1974.

. Bênção paterna - prefácio a 'Sonhos d'Ouro' [1872], in: COUTINHO, Afrânio (Org.). Caminhos do pensamento crítico. Vol.1, Rio de Janeiro: Ed. Americana/Prolivro, 1974.

BOURDIEU, Pierre. O poder simbólico. 2.ed., Rio de Janeiro: Bertrand Brasil, 1998.

CALDRE E FIÃO, José Antonio do Vale. A divina pastora. [1847] Apresentação de Flávio Loureiro Chaves. Porto Alegre: RBS, 1992

CLAVAL, Paul. O papel da nova geografia cultural na compreensão da ação humana, in: ROSENDHAL, Zeny; CORRÊA, Roberto Lobato. Matrizes da geografia cultural. Rio de Janeiro: Eduerj, 2001.

COUTINHO, Afrânio (Org.). Caminhos do pensamento crítico. Vol.1, Rio de Janeiro: Ed. Americana/Prolivro, 1974.

COSTA, Lobo da. Obra poética. [Lucubrações, 1874] Edição crítica por Alice Campos Moreira. Porto Alegre: IEL, 1991.

CUNHA, Delfina Benigna da. Poesias. [1843] Organizado por Carlos Alexandre Baumgarten. Porto Alegre: IEL, 2001.

DIAS, Gonçalves. Carta ao Dr. Pedro Nunes Leal, in: COUTINHO, Afrânio (Org.). Caminhos do pensamento crítico. Vol.1, Rio de Janeiro: Ed. Americana/Prolivro, 1974.

ESCOLAR, Marcelo. Crítica do discurso geográfico. São Paulo: Hucitec, 1996.

GOMES, Paulo César da Costa. O conceito de região e sua discussão, in: CASTRO, Iná Elias de et alii (orgs.). Geografia: conceitos e temas. 3.ed., Rio de Janeiro: Bertrand Brasil, 2001.

JOACHIMSTHALER, Jürgen. A literarização da região e a regionalização da literatura. Antares (Letras e Humanidades), n², jul/dez 2009.

LENCIONI, Sandra. Região e geografia. São Paulo: Edusp, 1999. 
LOPES NETO, JoãoSimões. Contos gauchescos [1912]. Edição comentada por Aldyr Garcia Schlee. Porto Alegre: Novo Século, 2000.

MAGALHÃES, Gonçalves de. Discurso sobre a história da literatura do Brasil [1836], in: COUTINHO, Afrânio (Org.). Caminhos do pensamento crítico. Vol.1, Rio de Janeiro: Ed. Americana/Prolivro, 1974.

RAFFESTIN, Claude. Por uma geografia do poder. São Paulo: Ática, 1993.

ROSA, João Guimarães. Sagarana. Rio de Janeiro: Record/Altaya, 1984.

SOUZA, Marcelo José Lopes de. O território: sobre espaço e poder, autonomia e desenvolvimento, in: CASTRO, Iná Elias de et alii (orgs.). Geografia: conceitos e temas. 3.ed., Rio de Janeiro: Bertrand Brasil, 2001.

TAVEIRA JÚNIOR, Bernardo. As provincianas [1873]. Porto Alegre: Movimento/Minc/INL, 1986.

ZILBERMAN, Regina. A terra em que nasceste: imagens do Brasil na Literatura. Porto Alegre: Editora da Universidade UFRGS, 1994 (Síntese Universitária, 41). 